\title{
Sacrocaudal Agenesis in a Korean Native Calf (Bos Taurus Coreanae)
}

\author{
Chong-Sup KIM ${ }^{1)}$, Phil-Ok $\mathrm{KOH}^{1,2)}$, Jae-Hyeon $\mathrm{CHO}^{1)}$, Oh-Sung PARK ${ }^{1)}$, Kyu-Woan $\mathrm{CHO}^{1)}$, Gon-Sup $\mathrm{KIM}^{1)}$ and \\ Chung-Kil WON ${ }^{1,2) *}$ \\ ${ }^{1)}$ College of Veterinary Medicine and ${ }^{2)}$ Institute of Agriculture and Life Science, Gyeongsang National University, Jinju 660-701, South \\ Korea
}

(Received 7 November 2006/Accepted 15 February 2007)

ABSTRACT. A male deformed Korean native calf was examined macroscopically. The deformed calf had no caudal vertebral columns from 5 th lumbar vertebra, sacrum and coccygeal vertebrae. The spinal cord was terminated in the vertebral foramen of the 3rd lumbar vertebra. The cervical vertebrae had scoliosis and the $3 \mathrm{rd}$ and 4 th cervical vertebrae were fused. The 2 nd and $3 \mathrm{rd}$ lumbar vertebrae were fused and the left and right transverse processes of the 4th lumbar vertebra articulated with ala of the ilium. The rectum was greatly expanded by the imperforate anus and a rectourethral fistula was formed between the rectum and urethra. The deformed calf was recorded as a first documentation of sacrocaudal agenesis confirmed in a Korean native calf.

KEY WORDS: deformation, Korean native calf, sacrocaudal agenesis.

A 2-day old male Korean native calf weighting $26 \mathrm{~kg}$ with a deformation, which exhibited difficulty in standing and walking, was submitted to the College of Veterinary Medicine, Gyeongsang National University for diagnostic evaluation. The dam of the affected calf, a 6-year-old Korean native cow, was raised in a farm in Goryong-ri, Jingyo-myeon, Hadong-gun, South Gyeongsang Province, has bred normal calves three times, and then bred a defective calf by artificial insemination.

On physical examination, the animal was found to be alert with an imperforate anus and a markedly distended rectum with fistulation between it and the urethra, which allowed small quantities of liquid rectal contents to enter the urethra. The hind limbs showed ankylosis, whereas the head, forelimbs and body were externally normal (Fig. 1).

The bone specimens showed that the vertebral columns of the deformed calf had 7 cervical, 13 thoracic, and 4 lumbar vertebrae. The caudal vertebral columns from the 5th lumbar vertebra, sacrum and coccygeal vertebrae were absent, indicating sacrocaudal agenesis. The cervical vertebrae had scoliosis and the 3 rd cervical vertebra was fused with the 4th cervical vertebra (Figs. 2A, 2B). The thoracic vertebrae and the 1 st lumbar vertebra were normal, whereas the 2 nd and 3rd lumbar vertebrae were asymmetrical between the left and right. The left transverse process and the vertebral arch of the 2nd lumbar vertebra were fused with the left surface of the 3rd lumbar vertebra (Fig. 2C). In the ventral surface, the 2 nd and 3 rd vertebrae were also partially fused (Fig. 2D). Transverse-process dorsalis major foramen in the left transverse process and transverse-process dorsalis minor foramen in the right transverse process of the 3rd lumbar vertebra were observed (Fig. 2C).

The left and right transverse processes of the 4th lumbar vertebra articulated with ala of the ilium, and were deformed

\footnotetext{
* Correspondence to: Won, C.K., Department of Anatomy, College of Veterinary Medicine, Gyeongsang National University, Jinju 660-701, South Korea.
}

like wing of sacrum. The spinal cord was extended only to the vertebral foramen of the 3rd lumbar vertebra.

The length of the specimens and organs were measured according to Driesch's method [4]. The hip bone was 163 $\mathrm{mm}$ long at the left side, and $167 \mathrm{~mm}$ at the right side, making it asymmetrical (Figs. 2E, 2F). The greatest breadth across the Tubera coxarum was $117 \mathrm{~mm}$, and the greatest breadth across the Tubera ischiadica was $49 \mathrm{~mm}$, with the ratio of $42 \%$.

The sacrocaudal agenesis calf with atresia ani showed a greatly expanded rectum (Fig. 3A). The expanded rectum measured $52 \mathrm{~cm}$ at the greater curvature and had a maximum girth of $24 \mathrm{~cm}$. At the end region of the expanded rectum, the rectourethral fistula was connected to the urethra at an area $37 \mathrm{~mm}$ from the neck of bladder (Figs. 3A, 3B).

This report is the first documentation of sacrocaudal agenesis in a Korean native calf in Korea. In the Holstein calf, the vertebrae were completely defective at the vertebral column from the 3rd thoracic vertebra to the caudal vertebrae [5]. Its spinal cord was terminated only to the 1 st thoracic vertebra, and from its 2 nd thoracic nerve, the associated muscles were contracted. Castro et al. reported that the Holstein calf had only to the 2nd lumbar vertebra, and from the 3rd lumbar vertebra to the caudal vertebrae were all defective [1]. In the present case, the Korean native calf showed defective caudal vertebrae from the 5th lumbar vertebra, sacrum, coccygeal vertebrae, and the spinal cord extended only to the 3rd lumbar vertebra. Therefore its vertebrae and spinal cord were present in the caudal region compared to that of Holstein calves. Moreover, it has been characterized with ankylosis of the joint in its pelvic limb and with contraction of its associated muscles, which coincides with the other reports $[1,3,6]$.

Leipold et al. mentioned that perosomus elumbis was accompanied by kyphosis (dorsal deviation), lordosis (ventral deviation), and scoliosis (lateral deviation) [7]. In this case, the 3 rd and 4 th cervical vertebrae were fused together 


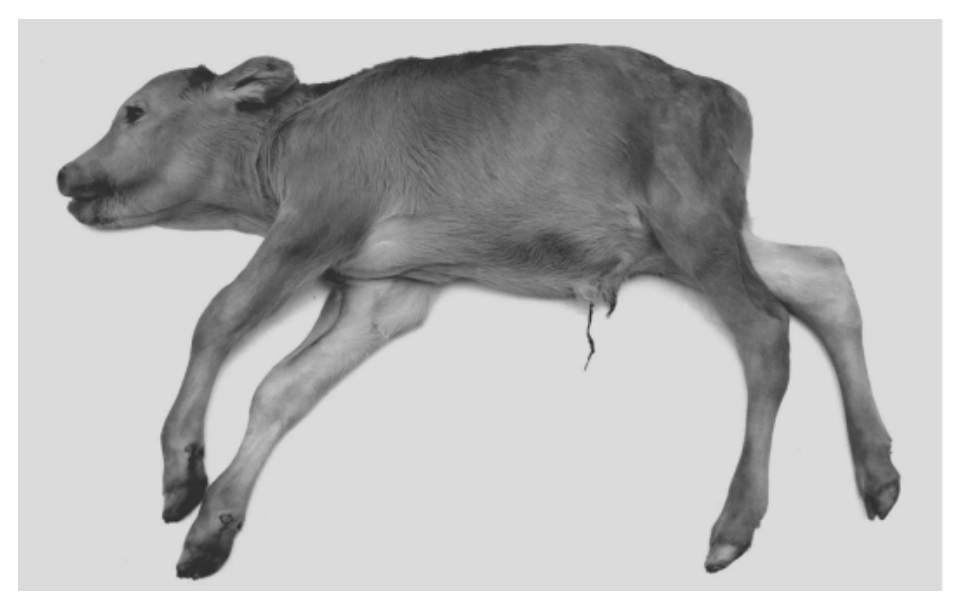

Fig. 1. Photomacrographs of 2-day-old Korean native calf with sacrocaudal agenesis.
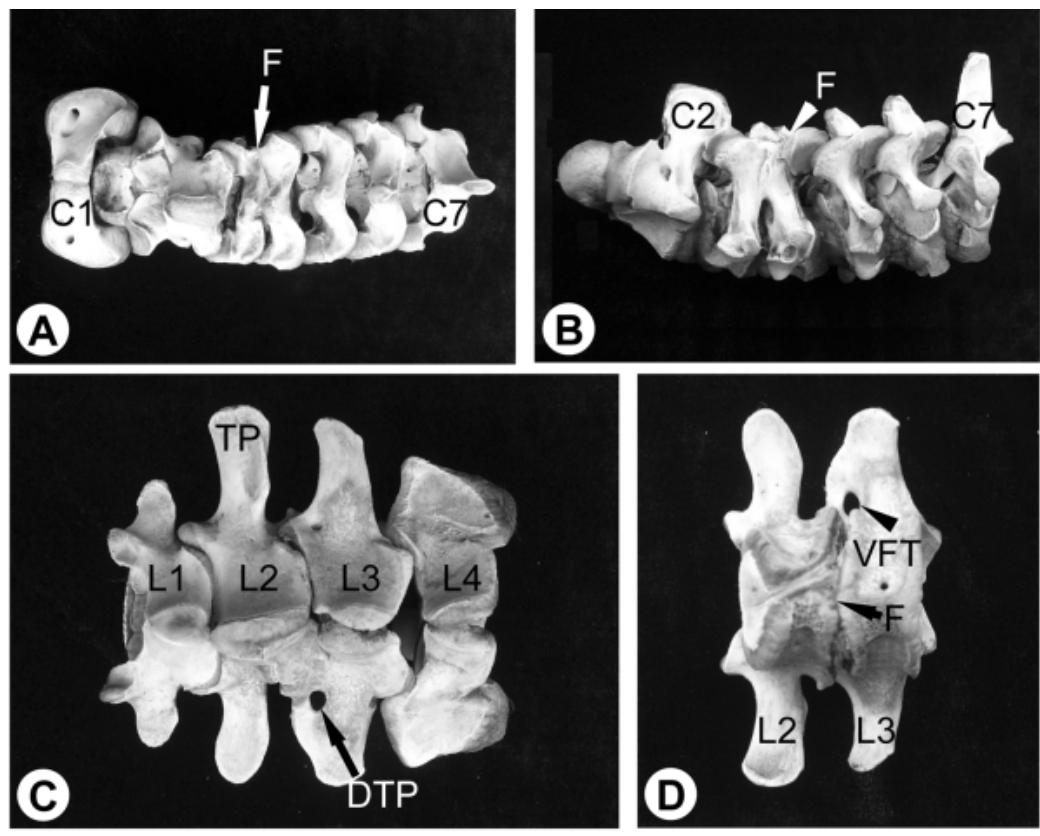

B

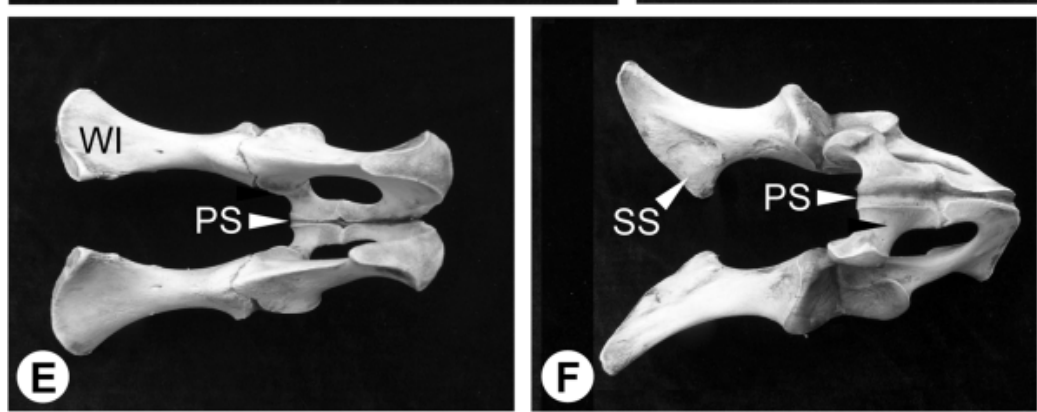

Fig. 2. Photomacrographs of the bone specimens in a deformed Korean native calf. A, B: Dorsal and lateral views of the cervical vertebrae. C, D: Dorsal and ventral views of the lumbar vertebrae. E, F: Dorsal and ventral views of the hip bones. C1: 1st cervical vertebra; C2: 2nd cervical vertebra; C7: 7th cervical vertebra; DTP: dorsal foramen of transverse process; F: fused region; L1-L4: 1st-4th lumbar vertebrae; PS: pelvic symphysis; SS: sacropelvic surface; TP: transverse process; VFT: ventral foramen of transverse process; WI: wing of ilium. 

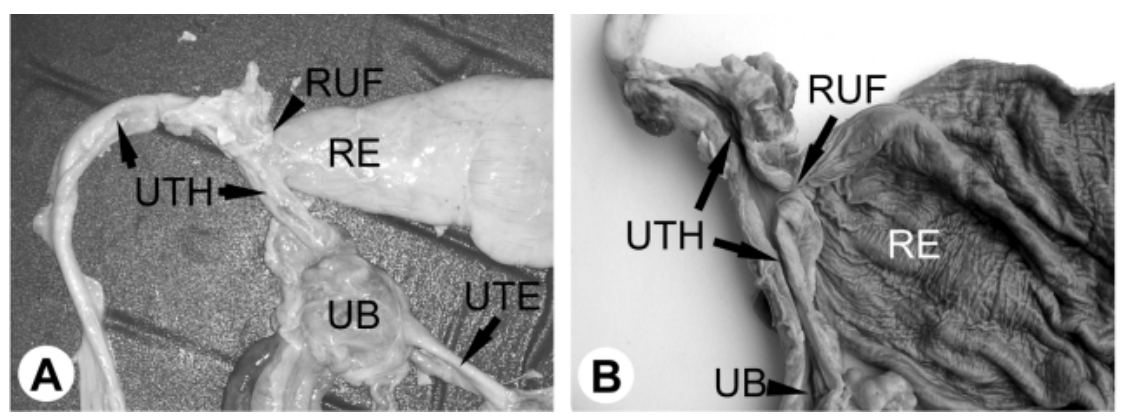

Fig. 3. Photomacrographs of rectourethral fistula in a Korean native calf. The rectum was greatly expanded by the imperforate anus and a rectourethral fistula was formed between the rectum and urethra. RE: rectum; RUF: rectourethral fistula; UB: urinary bladder; UTH: urethra; UTE: ureter.

indicating scoliosis.

The reports on the fusion of the vertebrae with perosomus elumbis involved the fusion of the 8th and 9th thoracic vertebrae of a Holstein calf [6]. In a Holstein calf, the iliums of both sides were fused, the pubis and ischium did not form pelvic symphysis [5], and the frontal regions of the ala of the ilium were fused together [6]. Castro et al. reported that there were no pubic bones, and the body trunk was directly connected to the hind limbs by soft tissues [1]. In this case, the cervical and lumbar vertebrae were fused, but the thoracic vertebrae were normal. The alas of the iliums were separated and articulate with the caudal surface of the left and right transverse processes in the 4th lumbar vertebra, presumably because the non-existence of the sacrum allowed the lumbar vertebrae to directly articulated with the ilium. Moreover, the right hip bone was longer than the left hip bone, and the greatest breadth across the tuber ischii was very small because the pelvic cavity was deformed. The pubis and ischium on both sides also showed pelvic symphysis.

Caudal vertebral defect such as perosomus elumbis was accompanied by atresia ani and agenesis of the urogenital and intestinal systems, thereby causing an improper arrangement of the internal organs within the abdominal cavity in a Holstein calf [5,6], a goat [2] and lambs [3]. The Korean native calf that was the subject of this study also had atresia ani. Moreover, the end region of the expanded rectum communicated with the urethra, indicating rectourethral fistula.

The causes of caudal vertebral defect have not yet been conclusively determined. However, Jones reported that genetic disorders in the development of the tail-bud stage allowed the malformation of the neural tube or improper migration to accompany the partial agenesis of the caudal spinal cord [6].

Another possibility is that such defect in an animal may be caused by chromosomal mutation in the Homeobox gene family [8]. On the other hand, Dennis mentioned (unpublished data) that a ewe at the 16th-17th day of pregnancy, which fed a plant (Veratrum californicum), gave birth to an offspring with perosomus elumbis [3]. Therefore, sacrocaudal agenesis may lead to the occurrence of the deformation not only due to genetic factors but also to environmental factors.

\section{REFERENCES}

1. Castro, M. B., Szabo, M. P., Hokamura, H. K. and Romano, M. A. 2003. Vet. Rec. 14: 753.

2. Cazabon, E. P., Loregnard, R. and Bridgewater, E. 1994. Vet. Rec. 135: 360.

3. Dennis, S. M. 1975. Aust. Vet. J. 51: 135-136.

4. Driesch, A. 1976. pp. 1-137. In: A Guide to the Measurement of Animal Bones from Archaeological Sites, Pub. Peabody Museum, Harvard Univ, U.S.A.

5. Hiraga, T. and Abe, M. 1983. J. Jpn. Vet. Med. Assoc. 36: $277-$ 279.

6. Jones, C. J. 1999. Vet. Pathol. 36: 64-70

7. Leipold, H. W., Huston, K. and Dennis, S. M. 1983. Adv. Vet. Sci. Comp. Med. 27: 197-271.

8. Noden, D. M. 1991. Brain Behav. Evol. 38: 190-225. 